\title{
Kinetics study of hydrochlorothiazide lactose liquid state interaction using conventional isothermal arrhenius method under basic and neutral conditions
}

\author{
Faranak Ghaderi'1,2, Mahboob Nemati' ${ }^{1,3}$, Mohammad Reza Siahi-Shadbad ${ }^{3,4}$, Hadi Valizadeh ${ }^{5}$, \\ Farnaz Monajjemzadeh ${ }^{4,3}$ *
}

\begin{abstract}
${ }^{1}$ Food and Drug Safety Research Center, Tabriz University of Medical Sciences, Tabriz, Iran, ${ }^{2}$ Department of Drug and Food Control, Urmia University of Medical Sciences, Urmia, Iran ${ }^{3}$ Department of Pharmaceutical and Food Control, Tabriz University of Medical Sciences, Tabriz, Iran, ${ }^{4}$ Drug Applied Research Center, Tabriz University of Medical Sciences, Tabriz, Iran ${ }^{5}$ Department of Pharmaceutics, Tabriz University of Medical Sciences, Tabriz, Iran
\end{abstract}

\begin{abstract}
The Maillard reaction of hydrochlorothiazide (HCTZ) and lactose has been previously demonstrated in pharmaceutical formulations. In this study, the activation energy of - hydrohlorothiazide and lactose interaction in the liquid state was ascertained under basic and neutral conditions. Conventional isothermal High Performance Liquid Chromatography (HPLC) technique was employed to ascertain the kinetic parameters using Arrhenius method. Results: The activation energy obtained was 82.43 and 100.28 $\mathrm{kJ} / \mathrm{mol}$ under basic and neutral conditions, respectively. Consequently, it can be inferred that Maillard reaction is significantly affected by $\mathrm{pH}$, which can be used as a control factor whenever the reaction potentially occurs.
\end{abstract}

Uniterms: Hydrochlorothiazide/lactose/Maillard reaction. Hydrochlorothiazide/lactose/interaction/ kinetic parameters. High Performance Liquid Chromatography (HPLC)/kinetic parameters study.

\section{INTRODUCTION}

Hydrochlorothiazide, chemically known as 6-chloro1,1-dioxo-3,4-dihydro- $2 H$-1,2,4-benzothiadiazine-7sulfonamide (Figure. 1) is an amine containing diuretic active ingredient that is often used in the treatment of high blood pressure and swelling due to fluid build-up. For high blood pressure, it is often prescribed as a first line treatment (Carlucci et al., 2000; Chaudhary et al., 2010; McCrea et al., 1995). HCTZ may be combined with other blood pressure medications as a single tablet for optimum efficacy.

The stability of the active ingredients of drugs is affected by different factors such as the nature of the excipients used and the environmental factors such as temperature, moisture, $\mathrm{pH}$ and light. Any undesired change in stability can affect the quality, safety and efficacy of the drug. Stress testing is a tool for detecting possible problems that are associated with the stability of the active

\footnotetext{
*Correspondence: F. Monajjemzadeh. Department of Pharmaceutical and Food Control. Tabriz University of Medical Sciences, 5166414766 - Tabriz, Iran. E-mail: monaggemzadeh@tbzmed.ac.ir / monajjemzadehf@yahoo.com
}<smiles>NS(=O)(=O)c1cc2c(cc1Cl)NCNS2(=O)=O</smiles>

FIGURE 1 - Chemical structure of HCTZ.

ingredients of a drug. It is also a tool for providing valuable data on the intrinsic stability of drug substances (Bakshi, Singh, 2002). When an incompatibility is detected in the initial steps, kinetic study would help to reveal more detailed information about the progress of the reaction.

Rate laws and rate constants are generally derived from chemical kinetic studies that involve experimental determination of reaction rate. Chemical reaction rates such as zero-order, first-order, second-order, mixed-order, or higher-order, fractional and negative order are often included. The activation energy for a reaction is usually determined experimentally using the Arrhenius equation. Reaction kinetic studies are often performed using HPLC 
(High Performance Liquid Chromatography) technique, which is highly sensitive, precise and reliable. It is however, time consuming and expensive.

In a survey, Harmon et al. (2000) characterized low levels of HCTZ-lactose condensation products that were formed by heating a wet mixture during Maillard reaction (Harmon et al., 2000). Different stability indicating HPLC methods have been reported in the determination of hydrochlorothiazide in pharmaceutical dosage forms (Lusina et al., 2005; Argekar, Sawant, 2000; Kanumula, Raman, 2000). Although degradation of HCTZ in aqueous solutions and its dependence on temperature and $\mathrm{pH}$ have been previously reported by Mollica, Rehm and Smith (1969), there is no kinetic assessment available for HCTZ and lactose interaction. In addition, no attention has been paid to the influence of $\mathrm{pH}$ on such interactions in drug molecules. Consequently, the present study was based on the kinetic assessment of HCTZ-lactose liquid state interaction using conventional isothermal Arrhenius method under basic and neutral $\mathrm{pH}$ conditions, which can be used as a control factor whenever the reaction potentially occurs.

\section{MATERIAL AND METHODS}

\section{Material}

HCTZ was obtained from Unichem (Maharashtra, India), anhydrous lactose was provided by DMV Chemical Co. (Veghal, Netherlands). HPLC grade methanol was purchased from DUKSAN (Gyeonggi-do, Korea); $\mathrm{KH}_{2} \mathrm{PO}_{4}$ and orthophosphoric acid were obtained from Merck (Darmstadt, Germany).

\section{HPLC (High Performance Liquid Chromatography)}

The Knauer HPLC system (Berlin, Germany) was made up of a Knauer controller quaternary pump and a UV detector (Knauer No. E 4310). The whole operation was controlled using EZ Chrome elite software. The HPLC method was a stability indicating method described by Bhagwate and Gaikwad (2013).

\section{RESULTS AND DISCUSSION}

Kinetic reaction study shows how different experimental conditions can affect the rate constant of chemical reactions. The rate constants and order of a reaction is usually obtained by experimental determinations. The order of reaction is the relationship between the concentration of reactants and the rate of a reaction. It indicates the extent to which the concentration of reactants affects the rate of reaction. The order of reaction for each reactant is often a positive whole number; however, they can sometimes be zero, fractional, mixed or negative. First-order reactions are the most common and imperative reactions in pharmaceutical reactions such as drug absorption and drug degradation (MOSS, 2013).

In zero-order reaction, the rate is independent of the concentration of the reactant and is based on equation 1 (Bett, Hall, 1968; Monajjemzadeh et al., 2014; Siahi-Shad Bad et al., 2016).

$$
[C]=-k t+[C]_{0} \quad \text { Equation } 1
$$

The plot of $[\mathrm{C}]$ against time was linear and the slope of the straight line was $-\mathrm{k}$.

First-order reaction rate depends on a single reactant concentration and the value of the exponent is 1 .

Equation 2 corresponds to the integrated form of the first-order reaction:

$$
\ln [C]=-k t+\operatorname{lm}[C]_{0} \quad \text { Equation } 2
$$

Plotting $\ln [\mathrm{C}]$ against time for a first-order reaction gives a straight line and the value of $-\mathrm{k}$ was computed from the slope of the straight line.

The rate of reaction for a second-order reaction depends on the square of the concentration or (more commonly) on the product of two concentrations. Equation 3 corresponds to this type of reaction:

$$
\frac{1}{[C]}=k t+\frac{1}{[C]_{0}} \quad \text { Equation } 3
$$

where $\mathrm{C}$ is the concentration of the reactant, $\mathrm{C}_{0}$ is the initial concentration of the reactant, $\mathrm{t}$ is time and $\mathrm{k}$ is the rate constant of the reaction (Kuo, 1986).

By 1880 , it was commonly known that the rate of a reaction increases with an increase in temperature; however, the reason for this phenomenon was not clear. Eventually, in 1889, the Swedish chemist Svante Arrhenius (18591927) combined the concepts of activation energy and the Boltzmann distribution law into one of the most valuable relationships for the dependence of reaction rates on temperature and presented the Arrhenius equation (Labuza, Riboh, 1982; Martin, Swarbrick, Cammarata, 1993).

The Arrhenius equation and the non-exponential form of this equation that is more conveniently used are presented as Equations 4 and 5:

$$
k=A e^{\frac{-E}{R T}} \quad \text { Equation } 4
$$




$$
\ln k=\ln A-\frac{E}{R T} \quad \text { Equation } 5
$$

where A is pre-exponential factor, e is a constant, approximately $2.7281, \mathrm{E}$ is the activation energy, $\mathrm{R}$ is the gas law constant: $8.314 \mathrm{~J} / \mathrm{mol}-\mathrm{K}, \mathrm{T}$ is the temperature $(\mathrm{K})$.

Consequently, the plotting of In $(\mathrm{k})$ against $1 / T$ gives a straight line; the activation energy $\left(\mathrm{E}_{\mathrm{a}}\right)$ and the pre-exponential factor (A) were obtained from the slope and the intercept of the Arrhenius plot.

In present study, the order of reaction was obtained after the residual amount of HCTZ was determined. As shown in Figure 2 and 3, the natural logarithm of a reactant concentration against time was linear in both basic and neutral conditions. The $\mathrm{pH}$ of the acidic and neutral samples were13.1 and 7.1, respectively. The values of the reaction rate coefficient $(\mathrm{k})$ were obtained from the slopes of the straight lines and presented in Table I. As expected, the temperature and time increased with a proportionate decrease in the HPLC peak areas.

$\mathrm{HCTZ}$ is an amine containing drug which can react with lactose to form Maillard reaction products (Harmon et al., 2000). In alkaline conditions, amino group present in its unionized form predominate and shows higher propensity to participate in a nucleophlic reaction such as Maillard reaction (Monajjemzadeh et al., 2009; Ghaderi et al., 2016a,b; Ghaderi et al., 2015a,b).

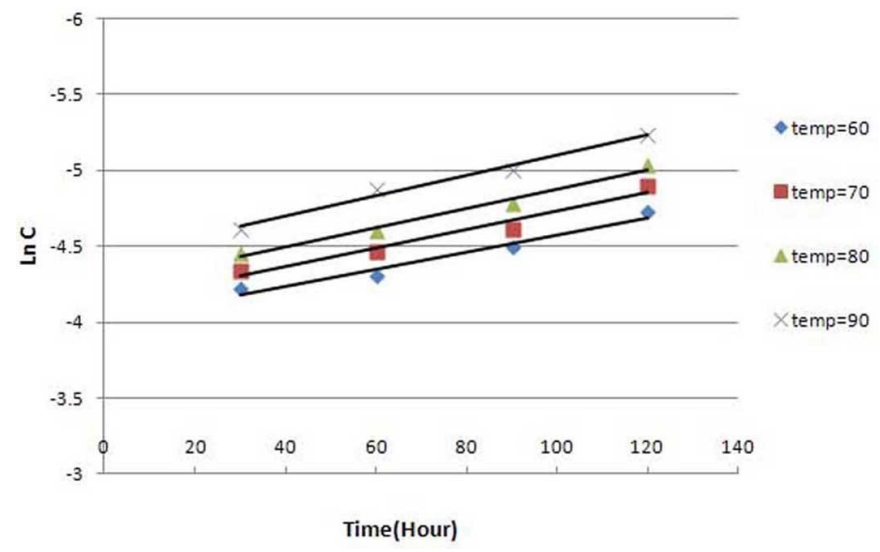

FIGURE 2 - The first order reaction plot of HCTZ-lactose liquid mixture at $\mathrm{pH}=13.1$ after $30,60,90$ and 120 minutes incubation at $60,70,80$ and $90^{\circ} \mathrm{C}$.

Activation energy (E) and pre-exponential factor were computed from the slope and intercept of the Arrhenius plot respectively from the line plot of $\operatorname{In}(k)$ against $1 / T$ (Figure 4 and 5). Furthermore, the kinetic parameters of the interaction were obtained and presented in Table II.

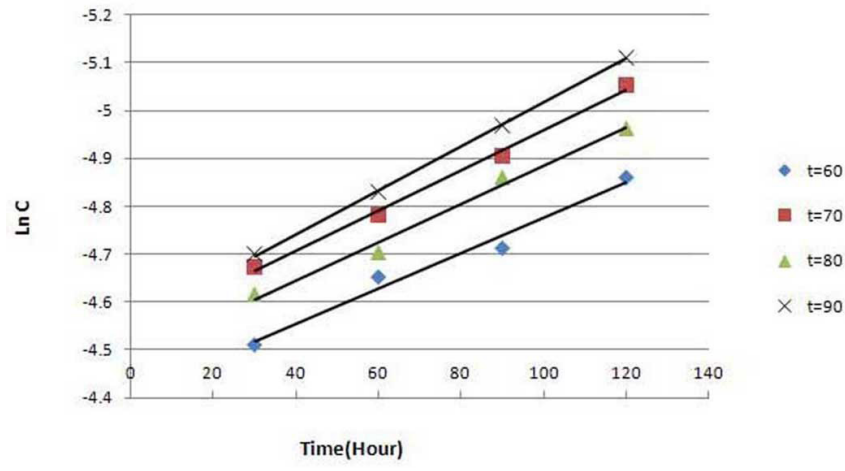

FIGURE 3 - The first order reaction plot of HCTZ-lactose liquid mixture at $\mathrm{pH}=7.1$ after $30,60,90$ and 120 minutes incubation at $60,70,80$ and $90^{\circ} \mathrm{C}$.

TABLE I - The values of reaction rate constants (k) and RSQ obtained from the order reaction plots of HCTZ-lactose liquid mixture at $\mathrm{pH}=13.1$ and 7.1 after $30,60,90$ and 120 minutes incubation at $60,70,80$ and $90^{\circ} \mathrm{C}$

\begin{tabular}{|c|c|c|c|c|}
\hline \multirow{9}{*}{$\begin{array}{l}\text { Zero order } \\
\text { reaction }\end{array}$} & pH & $\begin{array}{c}\text { Temperature } \\
\left({ }^{\circ} \mathrm{C}\right)\end{array}$ & $\mathbf{k}$ & $\begin{array}{c}\text { Mean } \\
\text { value of } \\
\text { RSQ }\end{array}$ \\
\hline & & 60 & $6.6051 \mathrm{E}-05$ & \multirow{4}{*}{0.9762} \\
\hline & 131 & 70 & $6.0768 \mathrm{E}-05$ & \\
\hline & 13.1 & 80 & 5.7051E-05 & \\
\hline & & 90 & 4.9519E-05 & \\
\hline & \multirow{4}{*}{7.1} & 60 & $3.4294 \mathrm{E}-05$ & \multirow{4}{*}{0.9901} \\
\hline & & 70 & $3.3273 \mathrm{E}-05$ & \\
\hline & & 80 & $3.2677 \mathrm{E}-05$ & \\
\hline & & 90 & $3.4051 \mathrm{E}-05$ & \\
\hline \multirow{9}{*}{$\begin{array}{l}\text { First order } \\
\text { reaction }\end{array}$} & pH & $\begin{array}{c}\text { Temperature } \\
\left({ }^{\circ} \mathbf{C}\right)\end{array}$ & $\mathbf{k}$ & $\begin{array}{c}\text { Mean } \\
\text { value of } \\
\text { RSQ }\end{array}$ \\
\hline & \multirow{4}{*}{13.1} & 60 & 0.0056 & \multirow{4}{*}{0.9823} \\
\hline & & 70 & 0.0060 & \\
\hline & & 80 & 0.0064 & \\
\hline & & 90 & 0.0067 & \\
\hline & \multirow{4}{*}{7.1} & 60 & 0.0036 & \multirow{4}{*}{0.9905} \\
\hline & & 70 & 0.0039 & \\
\hline & & 80 & 0.0041 & \\
\hline & & 90 & 0.0045 & \\
\hline \multirow{9}{*}{$\begin{array}{l}\text { Second order } \\
\text { reaction }\end{array}$} & pH & $\begin{array}{c}\text { Temperature } \\
\left({ }^{\circ} \mathbf{C}\right)\end{array}$ & $\mathbf{k}$ & $\begin{array}{c}\text { Mean } \\
\text { value of } \\
\text { RSQ } \\
\end{array}$ \\
\hline & \multirow{4}{*}{13.1} & 60 & 0.4983 & \multirow{4}{*}{0.9497} \\
\hline & & 70 & 0.6174 & \\
\hline & & 80 & 0.7425 & \\
\hline & & 90 & 0.9421 & \\
\hline & \multirow{4}{*}{7.1} & 60 & 0.4019 & \multirow{4}{*}{0.9837} \\
\hline & & 70 & 0.4796 & \\
\hline & & 80 & 0.5451 & \\
\hline & & 90 & 0.6207 & \\
\hline
\end{tabular}




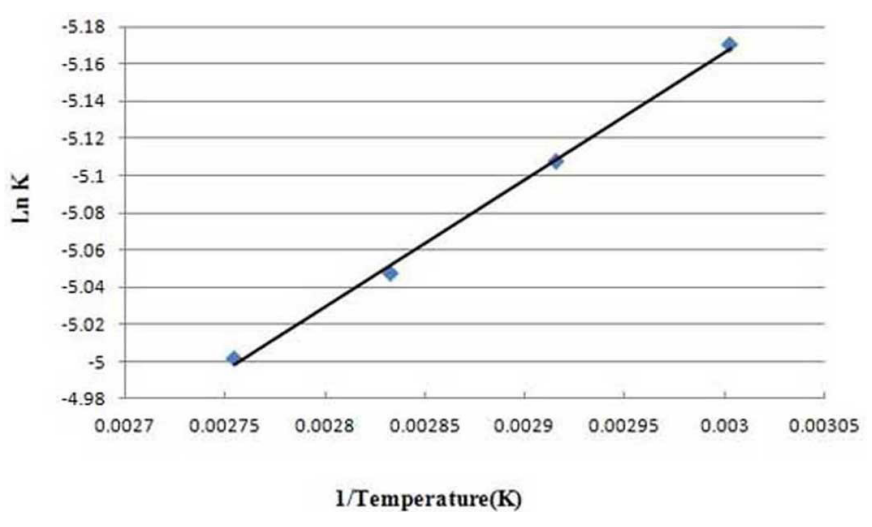

FIGURE 4 - Arrhenius plot of HCTZ-lactose liquid mixture at $\mathrm{pH}=13.1$.

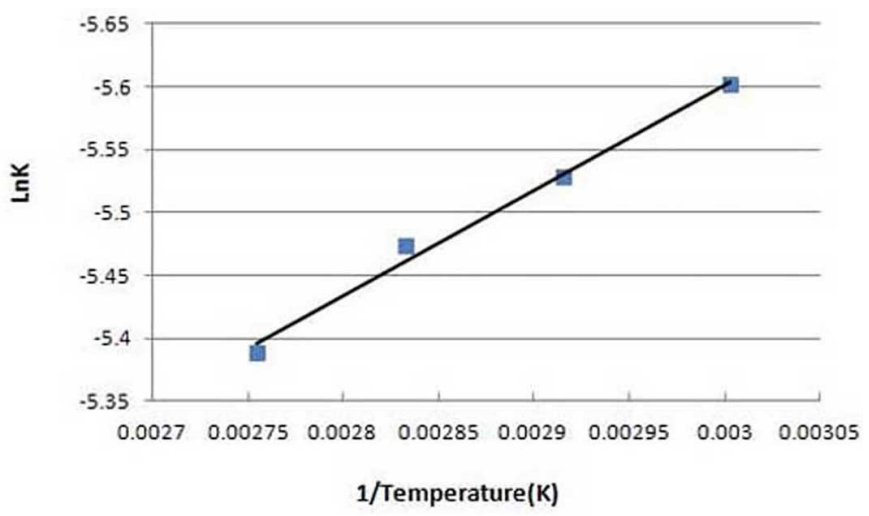

FIGURE 5 - Arrhenius plot of HCTZ-lactose liquid mixture at $\mathrm{pH}=7.1$.

TABLE II - Kinetic parameters of HCTZ-lactose liquid mixture interaction at $\mathrm{pH}=13.1$ and 7.1 obtained by conventional isothermal Arrhenius method

\begin{tabular}{lcccc}
\hline $\mathbf{p H}$ & Ea & Ln A & $\mathbf{K 2 5}^{\circ} \mathbf{C}$ & $\begin{array}{c}\mathbf{t 1} / \mathbf{2} \mathbf{2 5}^{\circ} \mathbf{C} \\
\text { (hour) }\end{array}$ \\
\hline 13.1 & 82.43 & -3.11 & 0.0051 & 135.29 \\
7.1 & 100.28 & -3.09 & 0.0031 & 221.71 \\
\hline
\end{tabular}

As seen in Table II, the calculated activation energy for HCTZ-lactose liquid state in basic and neutral conditions was 82.43 and $100.28 \mathrm{~kJ} / \mathrm{mol}$, respectively.

Several studies have been performed on this research theme. Oliveira, Ferraz and Matos (2005) determined the activation energies for interaction between glibenclamide and some excipients. According to their results, only one case of incompatibility was found between glibenclamide and magnesium stearate. The calculated activation energy for glibenclamide and magnesium stearate interaction was $106 \mathrm{~kJ} / \mathrm{mol}$ (Oliveira, Ferraz, Matos, 2005). In another study, Fulias et al. (2010), computed the activation energy for interaction between cefadroxil and magnesium stearate $(257.99 \pm 2.62 \mathrm{~kJ} / \mathrm{mol})$ (Fulias et al., 2010).

The increasing effect of $\mathrm{pH}$ on Maillard reaction was in consonance with the available non-pharmaceutical literature data.

Abul, Haider Shipar discovered in a study that Maillard reaction under basic conditions are most feasible for the generation of the Heyns rearrangement products between dihydroxyacetone and glycine in the initial stage (Shipar, 2006).

According to our result, the activation energy obtained for HCTZ-lactose at $\mathrm{pH} 7.1$ was $100.28 \mathrm{~kJ} / \mathrm{mol}$, which is less than that of glibenclamide-magnesium stearate and cefadroxil-magnesium stearate mixture. This is a clear indication of a higher probability of having an incompatibility between lactose and HCTZ. In addition, the activation energy in basic condition was greater than that in neutral $\mathrm{pH}$ condition indicating an increase in $\mathrm{pH}$ effect and basic condition on the Maillard reaction.

\section{CONCLUSION}

Kinetic assessment of HCTZ-lactose interaction known as a drug-excipient incompatibility reaction in pharmaceutical dosage forms that was based on isothermal heating method revealed small activation energies compared to other incompatibilities mentioned in the literature. It was shown that $\mathrm{pH}$ has a significant effect on the progress of a nucleophilic Maillard reaction. Finally, it can be concluded that $\mathrm{pH}$ variations may be employed as a control factor whenever the reaction potentially occurs.

\section{ACKNOWLEDGEMENT}

This work is a part of a thesis for the award of $\mathrm{PhD}$ degree (No. 91) by Faranak Ghaderi, and is supported by the faculty of Pharmacy, Tabriz University of Medical Sciences.

\section{REFERENCES}

ARGEKAR, A.; SAWANT, J. A gradient reversed phase High Performance Liquid Chromatography Method for simultaneous Determination of Hydrochlorothiazide (HCT) and Losartan Potassium (LOS) from tablets. Anal. Lett., v.33, n.5, p.869-880, 2000.

BAKSHI, M.; SINGH, S. Development of validated stabilityindicating assay methods -critical review. J. Pharm. Biomed. Anal., v. 28, n.6, p.1011-1040, 2002. 
BETT, J.A.; HALL, W.K. The microcatalytic technique applied to a zero order reaction: the dehydration of 2-butanol over hydroxyapatite catalysts. J. Catal., v.10, n.2, p.105-113, 1968.

BHAGWATE, S.; GAIKWAD, N. Stability indicating HPLC method for the determination of Hydrochlorothiazide in pharmaceutical dosage form. J. Appl. Pharm. Sci., v.3, n.2, p.88-92, 2013.

CARLUCCI, G.; PALUMBO, G.; MAZZEO, P.; QUAGLIA, M.G. Simultaneous determination of losartan and hydrochlorothiazide in tablets by high-performance liquid chromatography. J. Pharm. Biomed. Anal., v.23, n.1, p.185$189,2000$.

CHAUDHARY, A.B.; PATEL, R.K.; CHAUDHARY, S.A.; GADHVI, K.V. Estimation of valsartan and hydrochlorothiazide in pharmaceutical dosage forms by absorption ratio method. Int. J. Appl. Bio. Pharm. Tech., v.1, n.2, p. 455-464, 2010.

FULIAS, A.; VLASE, T.; VLASE, G.; SZABADAI, Z.; RUSU, G.; BANDUR, G.; TITA, D.; DOCA, N. Thermoanalytical study of cefadroxil and its mixtures with different excipients. Rev. Chem., v.4, p.1202-1206, 2010.

GHADERI, F.; NEMATI, M.; SIAHI-SHADBAD, M.R.; VALIZADEH, H.; MONAJJEMZADEH, F. DSC kinetic study of the incompatibility of doxepin with dextrose, application to pharmaceutical preformulation studies. $J$. Therm. Anal. Calorim., v.123, n.3, p.2081-2090, 2016 a.

GHADERI, F.; NEMATI, M.; SIAHI-SHADBAD, M.R.; VALIZADEH, H.; Monajjemzadeh, F. Physicochemical analysis and nonisothermal kinetic study of sertralinelactose binary mixtures. J. Food Drug Analysis, Article in press. 2016 b.

GHADERI, F.; NEMATI, M.; SIAHI-SHADBAD, M.R.; VALIZADEH, H.; MONAJJEMZADEH, F. Physicochemical evaluation and non-isothermal kinetic study of the drug-excipient interaction between doxepin and lactose. Powder Tech., v.286, p.845-855, 2015 a.

GHADERI, F.; NEMATI, M.; SIAHI-SHADBAD, M.R.; VALIZADEH, H.; MONAJJEMZADEH, F. Non isothermal decomposition kinetics and compatibility studies of doxepin with sucrose. Pharmind, v. 77, n.8, p.1222, 2015 b.
HARMON, P.A.; YIN, W.; BOWEN, W.E.; TYRRELL, R.; REED, R.A. Liquid chromatography - mass spectrometry and proton nuclear magnetic resonance characterization of trace level condensation products formed between lactose and the amine-containing diuretic hydrochlorothiazide. $J$. Pharm. Sci., v. 89, n.7, p.920-929, 2000.

KANUMULA, G.; RAMAN, B. Simultaneous determination of Hydrochlorothiazide and Losartan potassium in pharmaceutical dosage by reverse phase high performance liquid chromatography. Indian Drugs-Bombay., v.37, p.3841, 2000.

KUO, K.K. Principles of combustion. New York: John Wiley \& Sons, 1986.

LABUZA, T.; RIBOH, D. Theory and application of Arrhenius kinetics to the prediction of nutrient losses in foods [Degradation, keeping, quality, temperature, quality controls, analysis, models]. Food Tech., v.36, p.66-74, 1982.

LUSINA, M.; CINDRIĆ, T.; TOMAIĆ, J.; PEKO, M.; POZAIĆ, L.; MUSULIN, N. Stability study of losartan/ hydrochlorothiazide tablets. Int. J. Pharm., v.291, n.1-2, p.127-137, 2005

MARTIN, A.N., SWARBRICK, J.; CAMMARATA, A. Physical pharmacy: physical chemical principles in the pharmaceutical sciences, 1993. p.608-610.

MCCREA, J.B.; LO, M.W.; TOMASKO, L.; LIN, C.C.; HSIEH, J.Y.K.; CAPRA, N.L.; GOLDBERG, M.R. Absence of a pharmacokinetic interaction between losartan and hydrochlorothiazide. J. Clin. Pharm., v.35, n.12, p.12001206, 1995.

MOLLICA, J.; REHM, C.; SMITH, J. Hydrolysis of hydrochlorothiazide. J. Pharm. Sci., v.58, n.5, p.635$636,1969$.

MONAJJEMZADEH, F.; HASSANZADEH, D.; VALIZADEH, H.; SIAHI-SHADBAD, M.R.; MOJARRAD, J.S.; ROBERTSON, T.; ROBERTS, M.S. Assessment of feasibility of Maillard reaction between baclofen and lactose by liquid chromatography and tandem mass spectrometry, application to pre formulation studies. AAPS Pharm. Sci. Tech., v.10, n.2, p.649-659, 2009. 
MONAJJEMZADEH, F.; EBRAHIMI, F.; ZAKERI-MILANI, P.; VALIZADEH, $\mathrm{H}$. Effects of formulation variables and storage conditions on light protected vitamin $\mathrm{B} 12$ mixed parenteral formulations. Adv. Pharm. Bull., v.4, n.4, p.329$338,2014$.

MOSS, G. Kinetics and drug stability. In: DENTON, P.; ROSTRON, C.(Eds.) Pharmaceutics: the science of medicine design. Oxford: Oxford University Press, 2013.p.212-273

OLIVEIRA, G.; FERRAZ, H.; MATOS, J. Thermoanalytical study of glibenclamide and excipients. J. Therm. Anal. Calorim, v.79, n.2, p.267-270, 2005.
SHIPAR, M.A.H. Formation of the Heyns rearrangement products in dihydroxyacetone and glycine Maillard reaction: a computational study. Food Chem., v.97, n.2, p.231-243, 2006.

SIAHI -SHADBAD, M.R; GHADERI, F.; HATAMI, L.; MONAJJEMZADEH, F. Investigation of Possible Maillard Reaction Between Acyclovir and Dextrose upon Dilution Prior to Parenteral Administration. AAPS PharmSciTech., v.17, n.6. p.1491-1499, 2016.

Received for publication on $26^{\text {th }}$ July 2015 Accepted for publication on $03^{\text {rd }}$ October 2016 